\title{
AVALIAÇÃO DOS BENEFÍCIOS SECUNDÁRIOS DE PROJETOS MDL: CONTRIBUIÇÃO AO CONTROLE DE POLUIÇÃO E AO DESENVOLVIMENTO LOCAL E REGIONAL
}

\author{
P. C. Amaral' ${ }^{1}$ R. B. Correa ${ }^{2}$, H. M. Moreira ${ }^{3}$ \\ ${ }^{1}$ ICF International e Programa de Pós-Graduação em Planejamento Ambiental/COPPE-UFRJ \\ amaral.pc@gmail.com \\ ${ }^{2}$ Coordenadoria de Assistência Técnica Integral/Secretaria de Agricultura e Abastecimento do \\ Estado de São Paulo \\ ${ }^{3}$ Fundação Armando Álvares Penteado e das Faculdades Metropolitanas Unidas
}

Artigo submetido em janeiro/2011 e aceito em maio/2011

\section{RESUMO}

Considerando o aumento da importância de poluentes locais, regionais e globais nas atividades humanas, notados os acordos internacionais para controlar e reduzir as emissões de gases de efeito estufa destaca-se o Mecanismo de Desenvolvimento Limpo do Protocolo de Kyoto, como ferramenta para promover a redução de emissões de GEE e contribuir para o controle de poluição e desenvolvimento local e regional.Dentro do processo de aprovação de projetos de MDL no Brasil, existe a necessidade de se atender aos critérios relacionados à sustentabilidade local, definidos pelo governo brasileiro no documento denominado Anexo III. O presente estudo busca avaliar o processo que culminou com a definição dos critérios de sustentabilidade para projetos de MDL no Brasil e avaliar o impacto local e regional de projetos aprovados pelo governo brasileiro, no que concerne os poluentes ambientais $\mathrm{CO}$, NOx, SOx, MP e hidrocarbonetos, assim como impactos diretos à fauna, flora e recursos hídricos. Para a avaliação dos projetos foi proposta uma metodologia, baseada em metodologias previamente sugeridas para avaliação de projetos de MDL. Concluí-se que os critérios estabelecidos para o Anexo III contemplam, em essência, os critérios sugeridos nos trabalhos que antecederam sua definição. Por outro lado, é notável a diminuição do peso de benefícios secundários no mecanismo, como critérios obrigatórios ou classificatórios, quando se comparam as idéias originais àquelas que de fato foram implementadas.Ao mesmo tempo, devem ser valorizados os impactos secundários positivos advindos dos projetos de MDL, notados àqueles apresentados neste trabalho. Ressalta-se que os impactos ambientais positivos são extremamente relacionados ao menor consumo de combustíveis fósseis (não desconsiderando também a menor necessidade de produção dos mesmos) e aos impactos associados a estes combustíveis.

PALAVRAS-CHAVE: MDL, poluição global, poluição local, desenvolvimento sustentável 


\title{
ASSESSMENT OF SECONDARY BENEFITS OF CDM PROJECTS: CONTRIBUTION TO POLLUTION CONTROL AND TO LOCAL AND REGIONAL DEVELOPMENT
}

\begin{abstract}
Considering the increasing importance of local, regional and global pollutants on human activities, international agreements to control and reduce greenhouse gases (GHG) emissions should be noticed, and the Clean Development Mechanism of the Kyoto Protocol (CDM) should be highlighted as a tool to promote the reduction of GHG emissions and to contribute to pollution control and local and regional development.Within the approval process for CDM projects in Brazil, there is the need to meet criteria related to local sustainability, as defined by the Brazilian government in a document known as Annex III. This study aims to evaluate the process that culminated in the definition of sustainability criteria for CDM projects in Brazil and assess the impact of local and regional pollutants as a consequence of CDM projects approved by the Brazilian government, regarding CO, NOx, SOx, PM and hydrocarbons emissions, as well as direct impacts on fauna, flora and water resources. For the evaluation of the projects, a methodology was proposed, based on previously suggested methods for the assessment of CDM projects.Based on this study, it can be concluded that the criteria laid out on the document Annex III encompasses, in essence, the criteria suggested in the previous work that led up to its definition. Otherwise, it is remarkable the decrease of importance of secondary benefits, as mandatory or qualifying criteria to the approval process of CDM projects by the Brazilian Government, when comparing the original ideas to those that were actually implemented.At the same time, positive secondary impacts arising from CDM projects should be appraised. It is noteworthy that the positive environmental impacts are closely related to lower consumption of fossil fuels and related impacts.
\end{abstract}

KEY-WORDS: CDM, global pollution, local pollution, sustainable development 


\section{AVALIAÇÃO DOS BENEFÍCIOS SECUNDÁRIOS DE PROJETOS MDL: CONTRIBUIÇÃO AO CONTROLE DE POLUIÇÃO E AO DESENVOLVIMENTO LOCAL E REGIONAL}

\section{INTRODUÇÃO}

A poluição ambiental, de efeito local, regional ou global, tem ganhado cada vez mais importância nas agendas de governos e de instituições privadas. Poluentes têm sido notados, muitas vezes, como capazes de gerar ativos econômicos e não somente passivos. $\mathrm{O}$ agravamento do efeito estufa, com o consequente aumento da temperatura do planeta, fez com que nações se mobilizassem para alcançar um acordo internacional com o objetivo de reduzir a tendência de aquecimento. O resultado foi o Protocolo de Kyoto, que impulsionou um mercado internacional de redução de emissões de gases de efeito estufa, poluentes de ação global que são emitidos, principalmente, pela queima de combustíveis fósseis na geração de energia e pela queima de florestas em desmatamentos.

Não menos importantes, os poluentes de efeito local e regional, cujo controle tem tido a atenção das autoridades há mais tempo, seguem tendo relevante importância na gestão ambiental pública e privada. Dentro deste contexto, o mecanismo de desenvolvimento limpo (MDL), um dos mecanismos de flexibilização do Protocolo de Kyoto, que busca auxiliar países com metas de redução de emissões de GEE a atingi-las de forma custo-eficiente por meio de projetos em países em desenvolvimento, aborda a questão do desenvolvimento local e regional e, especificamente, a melhoria da sustentabilidade ambiental na região onde os projetos serão implementados.

Dentro do processo de aprovação de projetos de MDL no Brasil, existe a necessidade de se atender aos critérios relacionados à sustentabilidade local, que foram definidos e são confirmados pelo governo brasileiro, por meio de uma comissão específica. Este estudo busca avaliar o processo que culminou com a definição dos critérios de sustentabilidade para projetos de MDL no Brasil e, posteriormente, avaliar o impacto local e regional de projetos aprovados pelo governo brasileiro, no que concerne os poluentes ambientais $\mathrm{CO}, \mathrm{NOx}, \mathrm{SOx}$, MP e hidrocarbonetos, assim como impactos diretos à fauna, flora e recursos hídricos.

Para a avaliação dos projetos, foi proposta uma metodologia, baseada em metodologias previamente sugeridas para avaliação de projetos de MDL. Considerando que existe um gap of knowledge nas questões relacionadas ao controle da poluição global, i.e., dos GEE, e da sustentabilidade local (IPCC, 2007), este trabalho busca avaliar as principais inter relações e benefícios locais do MDL, concernentes à poluição local. Ressalta-se que se busca o entendimento da soma e do trade off de benefícios globais e benefícios locais e regionais, além do aprofundamento do primeiro critério de sustentabilidade exigido para projetos de MDL no Brasil, i.e., aquele relacionado à sustentabilidade ambiental local e regional.

\section{IMPACTO AMBIENTAL E POLUIÇÃO LOCAL, REGIONAL E GLOBAL}

Impacto ambiental é qualquer alteração das propriedades físicas, químicas e biológicas do meio ambiente, causada por qualquer forma de matéria ou energia resultante das atividades que, direta ou indiretamente, afetam: a saúde, a segurança e o bem-estar da população; as atividades sociais e econômicas; a biota; as condições estéticas e sanitárias do meio ambiente; a qualidade dos recursos ambientais (Resolução CONAMA n. 001, em LA ROVERE, E. L. 2009) 
Os impactos ambientais estão diretamente relacionados à poluição, que pode ser definida como a degradação da qualidade ambiental resultante de atividade que direta ou indiretamente:

a. Prejudiquem a saúde, a segurança e o bem-estar da população;

b. Criem condições adversas às atividades sociais e econômicas;

c. Afetem desfavoravelmente a biota;

d. Afetem as condições estéticas ou sanitárias do meio ambiente (Lei n. ${ }^{\circ} 6.938 / 81$, art. $3^{\circ}$, III, em SANTOS, M.A. 2009).

Em relação à poluição do ar, referencia é feita à presença de um ou mais poluentes atmosféricos, sendo poluente atmosférico toda e qualquer forma de matéria e/ou energia que, segundo suas características, concentração e tempo de permanência no ar, possa causar ou venha a causar danos à saúde, aos materiais, à fauna e a flora e seja prejudicial à segurança, ao uso e ao gozo da propriedade, à economia e ao bem - estar da comunidade (ABNT, 1985, em SANTOS, M.A. 2009).

A atmosfera é a massa de ar que rodeia a Terra, uma mistura de gases que constitui um invólucro, que envolve o planeta, possuindo varias camadas separadas em função de sua altitude. $\mathrm{O}$ ar atmosférico é composto por cerca de $78 \%$ de nitrogênio, $21 \%$ de oxigênio, sendo o restante (1\%) composto por gases como o argônio, dióxido de carbono e outros gases. Esta mistura de gases que compõem a atmosfera possui, naturalmente, uma determinada concentração típica de elementos, de forma que a poluição ambiental é caracterizada também como uma acentuação ou incremento dos níveis desta concentração, que sejam capazes de atingir concentrações nocivas ao ambiente.

Os poluentes ambientais são classificados em primários e secundários. Os primários são emitidos diretamente da fonte poluidora para a atmosfera e os secundários são formados na atmosfera por meio de reações químicas que ocorrem devido à presença de outras substancias e determinadas condições físicas (BRAGA, 2005). Entre os principais poluentes primários destacam-se:

- Monóxido de Carbono (CO): Composto gerado nos processos de combustão incompleta de combustíveis fósseis e outros materiais que contenham carbono em sua composição.

- Dióxido de Carbono $\left(\mathrm{CO}_{2}\right)$ : Principal composto resultante da combustão completa de combustíveis fósseis e de outros materiais combustíveis que contenham carbono. Também é gerado na respiração aeróbia dos seres vivos. É o gás de efeito estufa antrópico mais importante. Sua concentração atmosférica aumentou de um valor préindustrial de cerca de $280 \mathrm{ppm}^{1}$ para $379 \mathrm{ppm}$ em 2005, ultrapassando em muito a faixa natural dos últimos 650.000 anos, i.e., 180 a 300 ppm (IPCC, 2007).

- Óxidos de Nitrogênio (NOx): Resultante, principalmente, dos processos de combustão, que ocorrem na presença de oxigênio e nitrogênio presentes no ar. Também pode ser gerado por descargas elétricas (BRAGA, 2005).

${ }^{1}$ ppm (partes por milhão) é a relação do número de moléculas de GEE sobre o total de moléculas do ar seco. 
- $\quad$ Óxidos de Enxofre $\left(\mathrm{SO}_{2}\right.$ e $\left.\mathrm{SO}_{3}\right)$ : que contêm enxofre. Também

Produzidos por meio da queima de combustíveis naturais, no solo ou na água (BRAGA, 2005).

- $\quad$ Material Particulado (MP): Partículas de material sólido e liquido que são capazes de permanecer em suspensão, como poeira, fuligem, partículas de óleo ou pólen. Fuligem e partículas de óleo são originadas em processos de combustão.

- Hidrocarbonetos: Resultam da queima incompleta de combustíveis e de sua evaporação (BRAGA, 2005).

- Metano $\left(\mathrm{CH}_{4}\right)$ : Sua concentração atmosférica global aumentou de um valor préindustrial de cerca de $715 \mathrm{ppb}^{2}$ para $1732 \mathrm{ppb}$ no início da década de 90 , sendo de 1774 ppb em 2005. A concentração atmosférica de metano em 2005 ultrapassou em muito a faixa natural dos últimos 650.000 anos (320 a 790 ppb). É muito provável que o aumento observado da concentração de metano se deva às atividades antrópicas, predominantemente a agricultura e o uso de combustíveis fósseis (IPCC, 2007).

- Óxido nitroso $\left(\mathrm{N}_{2} \mathrm{O}\right)$ : A concentração atmosférica global de óxido nitroso aumentou de um valor pré-industrial de cerca de $270 \mathrm{ppb}$ para $319 \mathrm{ppb}$ em 2005. A taxa de aumento foi aproximadamente constante desde 1980. Mais de um terço de todas as emissões de óxido nitroso é antrópica, devendo-se principalmente à agricultura (IPCC, 2007).

Apenas citando alguns dos principais poluentes secundários tem-se: Ozônio Troposférico $\left(\mathrm{O}_{3}\right)$; Peróxido de Hidrogênio $\left(\mathrm{H}_{2} \mathrm{O}_{2}\right)$; Aldeídos; Peroxiacetilnitratos (BRAGA, 2005), que não são abordados neste estudo.

As fontes de poluição são classificadas em móveis, quando produzem poluentes de forma dispersa no espaço (e.g. automóvel) e estacionárias, quando produzem cargas pontuais de poluentes (e.g. chaminé de uma fábrica).

Alguns poluentes possuem ação global, enquanto outros afetam, principalmente, a região na qual são emitidos. Problemas ambientais de caráter local, ocasionados por poluição aérea, podem ter como conseqüências:

- $\quad$ Efeitos negativos sobre a saúde das populações;

- Danos aos materiais e às construções;

- $\quad$ Alterações microclimáticas;

- Danos aos animais e plantas (incluindo eliminação da vida aquática, pelo aumento constante dos níveis de acidez, nos lagos, por exemplo).

Problemas ambientais de caráter regional ou continentais são observáveis a grandes distâncias das fontes emissoras. Podem ser destacados, entre os principais impactos ocasionados por poluentes de ação regional ou continental:

- $\quad$ Acidificação da atmosfera, por deposição ácida ou chuva ácida.

${ }^{2}$ ppb (partes por bilhão) é a relação do número de moléculas de GEE sobre o total de moléculas do ar seco. 
Problemas ambientais globais decorrentes da poluição aérea afetam parâmetros de grande escala da atmosfera. Destaque é dado às seguintes conseqüências:

- Intensificação do efeito estufa e conseqüente aquecimento global;

- $\quad$ Destruição da camada de ozônio (SANTOS, M. A., 2009).

Devem ser notados também os impactos relacionados à produção dos combustíveis fósseis, com destaque, neste trabalho, ao carvão e derivados de petróleo, que acentuam os impactos ambientais locais já mencionados.

Dentro do processo de mineração e lavagem do carvão, podem ser citados os impactos seguintes:

- $\quad$ Saúde dos trabalhadores nas minas;

- $\quad$ Risco de Acidentes: Incêndios, explosões;

- $\quad$ Erosão e Acidificação do Solo;

- $\quad$ Drenagem Ácida - Eliminação/Redução da vida nos recursos hídricos;

- Impactos negativos sobre os assentamentos humanos e sua Infra-Estrutura;

- $\quad$ Contaminação do ar (NOx, SOx, MP);

- $\quad$ Contaminação da Água (Finos de carvão em suspensão);

- $\quad$ Inutilização de grandes áreas para depósitos de rejeitos;

-

- $\quad$ Risco de combustão espontânea dos rejeitos (LA ROVERE, E. L., 2009).

Mencionando os impactos da exploração e produção de petróleo e gás natural, pode-se citar:

- $\quad$ Risco de incêndios, explosões e vazamento;

- $\quad$ Pequenos vazamentos;

- Risco de grandes Vazamentos, explosões e incêndios em oleodutos, gasodutos e tanques de armazenamento;

- $\quad$ Emissões de SOx, NOx, CO, MP e compostos orgânicos;

- $\quad$ Odor desagradável

- Efluentes líquidos tóxicos, com óleo, fenóis, amônia, graxa e sólidos em suspensão ou dissolvidos (LA ROVERE, E. L., 2009).

Os gases de efeito estufa (GEE), e.g. dióxido de carbono, óxido nitroso e metano, são classificados como poluentes globais, tendo em vista que o aumento de sua concentração na atmosfera traz consequências sentidas globalmente. As mudanças na quantidade de gases de 
efeito estufa e aerossóis da atmosfera, na radiação solar e nas propriedades da superfície terrestre alteram o equilíbrio energético do sistema climático (IPCC, 2007). As evidências obtidas por meio de observações de todos os continentes e da maior parte dos oceanos mostram que muitos sistemas naturais estão sendo afetados pelas mudanças climáticas regionais, principalmente pelos aumentos de temperatura (IPCC, 2007).

Os GEE auxiliam o aquecimento e manutenção da temperatura no planeta, formando um "cobertor" que força parte da energia proveniente do sol a ficar retida nas proximidades da Terra, o que viabiliza a vida no planeta. A energia proveniente do sol chega ao planeta em ondas curtas, e tem parte absorvida principalmente pela superfície da Terra. Essa energia é redistribuída pela circulação atmosférica e oceânica e radiada ao espaço em comprimentos de ondas mais longos (radiação infravermelha). Sem o efeito estufa natural estima-se que a superfície da Terra teria temperatura média cerca de $30^{\circ} \mathrm{C}$ inferior a observada hoje. De forma geral, existe um equilíbrio entre radiação recebida e devolvida e qualquer fator que altere este equilíbrio, atuando tanto na chegada como na saída da radiação, pode ser fonte de alteração do clima. Esta mudança na energia disponível para o sistema Terra é expressa em termos de forçamento radiativo. A variação da concentração de gases na atmosfera tem diminuído a capacidade de resfriamento do planeta, causando um forçamento radiativo que tende a aquecer a baixa atmosfera e a superfície, intensificando o efeito estufa natural. $\mathrm{O}$ total de aquecimento irá depender da elevação das concentrações dos GEEs, suas respectivas propriedades radiativas e as concentrações destes gases já presentes na atmosfera. Modelos meteorológicos de previsão que avaliam GEEs, atividade solar, propriedades da superfície e alguns aspectos dos aerossóis levaram à melhora de estimativas quantitativas do forçamento radiativo (IPCC, 2007).

Desde a Revolução Industrial, no século XVIII, a queima de carvão mineral e petróleo vêm liberando quantidades crescentes de $\mathrm{CO}_{2}$. Desmatamento, acúmulo de lixo e esgoto, processos industriais, práticas cada vez mais intensiva de agricultura (desmatamentos, o cultivo de arroz, utilização de fertilizantes nitrogenados) e da também mais intensiva pecuária (por meio dos processos digestivos dos animais e da decomposição de seus dejetos) contribuem para o aumento da emissão de alguns dos GEE.

Desta forma, destaque tem sido dado aos poluentes globais, i.e. GEE, em função do amplo reconhecimento científico de que sua concentração atmosférica tem aumentado ao longo do tempo, em função de atividades humanas. As concentrações atmosféricas globais de dióxido de carbono, metano e óxido nitroso aumentaram bastante em conseqüência das atividades humanas desde 1750, e agora ultrapassam em muito os valores pré-industriais determinados com base em testemunhos de gelo de milhares de anos. Os aumentos globais da concentração de dióxido de carbono se devem principalmente ao uso de combustíveis fósseis e à mudança no uso da terra. Já os aumentos da concentração de metano e óxido nitroso são devidos principalmente à agricultura (IPCC, 2007).

Diversos efeitos ocasionados pela variação climática poderão ocorrer, sendo alguns destes mencionados abaixo:

- Dias e noites frios em menor quantidade e mais quentes na maior parte das áreas terrestres;

- Dias e noites quentes mais freqüentes e mais quentes na maior parte das áreas terrestres; 
- Surtos de calor/ondas de calor. A frequiência aumenta na maior parte das áreas terrestres;

- $\quad$ Eventos de precipitação extrema;

$\bullet$

- A área afetada pelas secas aumenta;

$\bullet$

- A atividade intensa dos ciclones tropicais aumenta;

- $\quad$ Aumento da incidência de nível extremamente alto do mar (IPCC, 2007).

Brevemente descritos os principais poluentes primários locais e globais, indicadas suas origens e principais efeitos, no próximo item será feita referência ao Protocolo de Kyoto, notório acordo internacional para lidar com a questão do clima. Dentro deste contexto, i.e., de um acordo internacional que busca estabilizar a concentração de poluentes de efeito global, será dado enfoque a um de seus mecanismos de flexibilização, o Mecanismo de Desenvolvimento Limpo (MDL), que busca tratar das emissões de poluentes globais em nações em desenvolvimento.

\section{A CONVENÇÃO QUADRO DAS NAÇÕES UNIDAS SOBRE MUDANÇAS CLIMÁTICAS (CQNUMC) E A CONFERÊNCIA DAS PARTES (COP)}

Os problemas ambientais globais começaram a fazer parte da agenda internacional com a Conferência de Estocolmo em 1972 (MOREIRA, 2005). A primeira conferência Global sobre o clima foi realizada em 1979, pela Organização Meteorológica Mundial da ONU (WMO, sigla em inglês). Em 1988 foi estabelecido, conjuntamente pela organização meteorológica Mundial e pelo Programa das Nações Unidas para o Meio Ambiente (PNUMA), o Painel Intergovernamental sobre Mudança Climática (IPCC) com os objetivos de: (I) avaliar as informações científicas existentes sobre mudança do clima, (II) avaliar os impactos ambientais e socioeconômicos da mudança do clima e (III) formular estratégias e propostas (IPCC, 1995, em AMARAL, P.C., 2007). As discussões e os trabalhos prosseguiram até a realização, em 1990, do Primeiro Relatório de Avaliação do IPCC, com a subseqüente constituição do Comitê Negociador Internacional para uma Convenção sobre Mudança do Clima. O IPCC constitui-se em uma autoridade internacional na questão, fornecendo subsídio científico, influenciando a opinião pública mundial e as negociações internacionais que tratam da mudança climática, como as negociações da Convenção Quadro das Nações Unidas sobre Mudança do Clima (CQNUMC). Tomou corpo no ano de 1990 a Segunda Conferência Mundial Sobre o Clima, estabelecendo-o como ano-base para formulação das políticas posteriores. A cada cinco anos o IPCC formula novo relatório com dados atualizados, na tentativa de congregar o que de mais moderno foi produzido sobre a questão do clima no mundo científico.

Em 1992, durante a Conferência das Nações Unidas sobre Meio Ambiente e Desenvolvimento (CNUMAD, conhecida como Rio 92) foi assinada a Convenção do Clima, que teve como objetivos: alcançar a estabilização de gases de efeito estufa na atmosfera e impedir a interferência antrópica no sistema climático. Estabelecendo as "responsabilidades comuns, porém diferenciadas" como princípio definidor do regime internacional de mudanças climáticas. A Convenção do Clima divide os países participantes (Partes) em dois grupos, nos quais ocorre tratamento diferenciado aos países que historicamente emitiram mais GEE 
(países industrializados) e países que têm menores responsabilidades sobre o aumento das emissões (países em desenvolvimento).

Aos países signatários da Convenção Quadro das Nações Unidas ocorre, anualmente, a Conferência das Partes (COP), que é o órgão supremo da Convenção e ao qual cabe estabelecer as regras de implementação das decisões tomadas pelas Partes.

As COPs que merecem destaque nesse trabalho são a de número 3, ocorrida em 1997, em Kyoto, Japão, quando foi assinado o Protocolo de Kyoto e a COP 7, de Marraquesh, Marrocos, em outubro de 2001, onde foram definidas regras do Conselho Executivo do MDL; credenciamento das entidades operacionais; definição do documento de concepção do projeto (DCP), e a definição dos critérios de elegibilidade dos projetos de MDL, entre outros.

\section{PROTOCOLO DE KYOTO}

O Protocolo de Kyoto é um acordo internacional patrocinado pela ONU que foi adotado em 1997 por 59 países, na cidade de Kyoto, Japão, e passou a vigorar em fevereiro de 2005, depois de atendido um pré-requisito de ser ratificado ao menos por países que representassem 55\% do total de emissões de GEEs, fato que ocorreu após a Rússia, em novembro de 2004, formalizar sua adesão. Assim, o Protocolo contou com a adesão de 141 países, que juntos correspondiam a $61,6 \%$ das emissões globais.

Seguindo o "princípio das responsabilidades comuns, porém diferenciadas", define-se que a responsabilidade pelo aquecimento global é de todas as nações, porém que os responsáveis pela maior parte das emissões (países industrializados), deveriam ser os maiores responsáveis por suas reduções. Os países foram, assim, divididos em dois grupos: países- Parte do Anexo 1, os países industrializados membros da OCDE - Organização para a Cooperação e Desenvolvimento Econômico - e países ex-comunistas, e países Não-Parte do Anexo 1, os países em desenvolvimento (os países do Anexo 1 respondem, juntos, por 96\% das emissões de gases de efeito estufa). O Protocolo estabeleceu, para os países do Anexo 1, metas para a redução de emissão de gases de efeito estufa de $5 \%$, em média, usando como referência o nível das emissões do ano-base de 1990, no período compreendido entre 2008 - 2012, enquanto os países não-partes do Anexo 1 não possuem compromissos de redução. Esses cinco anos são conhecidos como o primeiro período de compromisso e para o segundo período ainda não foram estabelecidas metas de redução. Em seu processo negociador, o Protocolo envolveu questões não só ambientais, mas também políticas e econômicas, visto que o setor industrial poluidor teria que ser modificado e, por afetar praticamente todos os setores da economia, é considerado o acordo sobre meio ambiente e desenvolvimento sustentável mais importante e de maior projeção já adotado até hoje (MOREIRA, 2005).

O Protocolo estipula três mecanismos de flexibilização, arranjos técnico-operacionais regulamentados que buscam auxiliar o cumprimento das metas estabelecidas, da forma mais barata. São esses: Comércio de Emissões, Implementação Conjunta e Mecanismo de Desenvolvimento Limpo. O Comércio de Emissões permite que países que consigam reduzir emissões além da meta nacional (que varia conforme o país), possam negociar este excesso na forma de créditos com outros países, criando um comércio internacional de emissões entre países do Anexo 1 (únicos com meta de redução). Os Projetos de Implementação Conjunta permitem que um país do Anexo 1 invista em outro país do Anexo 1, em projetos que comprovadamente colaborem para a redução dos gases. Outro mecanismo, proposto pelo Brasil e que possibilita a entrada de países em desenvolvimento nas negociações de carbono, é 
o Mecanismo de Desenvolvimento Limpo (MDL). Não apenas governos, mas instituições privadas podem participar diretamente desses projetos.

É interessante notar que o protocolo e seus mecanismos de flexibilização originam um sistema híbrido de controle de poluição global, i.e., por um lado, um acordo internacional estabelecendo metas de emissões de forma semelhante aos padrões de emissões de poluentes estabelecidos nacionalmente para indústrias por meio de mecanismos de comando e controle. Já os mecanismos de flexibilização assemelham-se aos mecanismos de mercado para controle de poluição, nos quais, ao invés de punições, premia-se àqueles que reduzam as emissões de poluentes.

\section{MECANISMO DE DESENVOLVIMENTO LIMPO (MDL)}

Proposto à Convenção Quadro da Mudança do Clima pelo Brasil, o MDL oferece aos países em desenvolvimento signatários do Protocolo de Kyoto (países não-Parte do Anexo 1), a possibilidade de prestar assistência aos países do Anexo 1 no cumprimento de suas metas de redução, por meio de projetos devidamente certificados que contribuam para o objetivo final da Convenção. Ao mesmo tempo, o MDL busca ser um mecanismo que promova o desenvolvimento sustentável nos países de onde os projetos serão implementados. Estes devem buscar formas de redução das emissões de GEE ou o aumento da remoção destes gases, via investimento em tecnologias ambientalmente mais evoluídas, substituição de fontes de energia fósseis por renováveis, racionalização no uso da energia, reflorestamento, florestamento, entre outras alternativas.

O MDL é fundado em princípios de um mecanismo bilateral representado pelas Atividades Implementadas Conjuntamente entre países do Anexo I e não-Anexo I, e na criação de um mecanismo de mercado capaz de ligar projetos de redução de GEE em países não-Partes do Anexo I aos investidores dos países do Anexo I, creditando as reduções obtidas.

O MDL é definido pelo Artigo 12 do Protocolo de Kyoto e tem como objetivo principal (Art. 12.2): "Assistir às Partes não incluídas no Anexo I para que atinjam o desenvolvimento sustentável e contribuam para o objetivo final da Convenção, e assistir às Partes incluídas no Anexo I para que cumpram seus compromissos quantificados de limitação e redução de emissões, assumidos no artigo 3" (MCT, 1997).

Em troca do investimento em "projetos limpos", os países do Anexo I receberiam Certificados de Redução de Emissões (CREs), das quais fariam uso no cumprimento das metas de redução. Entidades Operacionais Designadas (EODs), credenciadas junto à ONU, são as certificadoras destes projetos, com a missão de garantir que um projeto gerador de CREs traga benefícios mensuráveis, reais e de longo prazo relacionados à mitigação da mudança do clima.

O MDL segue a seguinte estrutura institucional:

I. Conferência das Partes COP/MOP (Conference of the Parties serving as the Meeting of the Parties to the Kyoto Protocol) - que exerce a autoridade sobre o MDL

II. Conselho Executivo - exerce a supervisão e é auxiliada pelos:

III. Painéis - de Credenciamento e de Metodologias 
IV. Grupos de Trabalho de florestas e de projetos de pequena escala

V. Autoridades Nacionais Designadas (AND)

VI. Entidades Operacionais Designadas (EOD) - realizam a validação e verificação dos projetos.

No Brasil a AND é a Comissão Interministerial de Mudança Global do Clima - CIMGC, estabelecida por Decreto Presidencial em 7 de julho de 1999. A CIMGC é formada por diversos Ministérios, presidida pelo Ministério da Ciência e Tecnologia, com o Ministério de Meio Ambiente exercendo a vice-presidência. Compõem-na representantes dos Ministérios das Relações Exteriores; da Agricultura, Pecuária e Abastecimento; dos Transportes; das Minas e Energia; do Planejamento, Orçamento e Gestão; do Desenvolvimento, Indústria e Comércio Exterior; das Cidades; da Fazenda e da Casa Civil da Presidência da República. A secretaria executiva da Comissão é desempenhada pelo Ministério da Ciência e Tecnologia. Dessa maneira, a comissão conta com representantes de todos os setores de atividades descritos no Anexo A do Protocolo de Kyoto, que classifica os setores de atividades e as categorias de fontes de emissão de GEE.

Para que gerem os CREs, os projetos precisam passar por um ciclo definido, até que sejam registrados no Conselho Executivo do MDL. Os seguintes passos devem ser cumpridos:

1. O proponente do projeto deve elaborar o Documento de Concepção do Projeto (DCP);

2. A Entidade Operacional Designada (EOD) deve validar a o DCP;

3. A Autoridade Nacional Designada (AND) deve aprovar o projeto proposto, emitindo a carta de aprovação;

4. O projeto deve ser, em seguida, registrado no Conselho Executivo do MDL (CE);

5. A Entidade Operacional Designada (EOD) realiza a verificação e certificação da redução de emissões resultantes do projeto;

6. O Conselho Executivo do MDL (CE) emite a Redução Certificada de Emissão (RCE).

Para que as EODs certifiquem as reduções de emissões resultantes de cada atividade de projeto, o projeto deve obedecer alguns critérios: deve vir de uma participação voluntária (o projeto não pode, por exemplo, ser fruto de uma obrigação por lei); deve trazer benefícios reais, mensuráveis e de longo prazo relacionados com a mitigação da mudança do clima; e as reduções de emissões devem ser adicionais às que ocorreriam na ausência da atividade proposta (saldo negativo entre emissões de um projeto viável sem o subsídio do MDL e as emissões considerando o projeto proposto).

A ciência do clima tem evoluído e cada vez mais se compreendem os processos pelos quais passam os GEEs, assim como suas conseqüências. Utilizando o que existe de consenso junto à comunidade internacional, o projeto tão somente será aprovado se houver garantias de seu beneficio ambiental. Ponto fundamental da aprovação de qualquer projeto de MDL é a comprovação de que de fato ele não seria implementado sem os incentivos do MDL. 
O Documento de concepção do Projeto deve ser elaborado pelo proponente do projeto e conter as seguintes informações: descrição geral do projeto, metodologia de linha de base a ser utilizada, prazo do projeto, metodologia e plano de monitoramento, estimativa de emissões de GEEs, impactos ambientais do projeto, comentários dos participantes envolvidos, informações sobre fontes de financiamento público de partes do Anexo I para o projeto.

A linha de base, relatada acima, é o nível atual e a evolução das emissões de GEE que ocorreriam caso o projeto não fosse implantado, e deve ser avaliada de forma dinâmica. Tal cenário será utilizado para o cálculo da redução de emissões, que são os créditos, passíveis de geração pelo projeto.

A comercialização ocorre através da quantidade de carbono equivalente que deixa de ser emitida ou é absorvida. Com uso da equivalência de GWP (Potencial de Aquecimento Global, ou Global Warming Potential em inglês), as reduções obtidas com outros GEE são transformadas em toneladas de dióxido de carbono equivalente, o que padroniza a mercadoria de troca, facilitando a negociação. O MDL deve estimular o desenvolvimento sustentável e a redução de emissões, ao mesmo tempo em que oferece flexibilidade aos países com metas de redução de emissões na forma como atingirão tais metas.

Considerando as informações mencionadas acima, ressalta-se que os projetos precisam ser qualificados por meio de um rigoroso processo público de registro e emissão de créditos e que as ANDs devem aprovar os projetos, para que se qualifiquem à fase seguinte do MDL, de registro junto ao CE. A aprovação das ANDs consolida-se com a emissão de uma Carta de Aprovação. No Brasil, a emissão da Carta de Aprovação ocorre após a confirmação de que o projeto encontra-se em sintonia com questões definidas nas resoluções da CIMGC. Dentro dos itens estipulados pela comissão, estão aqueles relacionados ao desenvolvimento sustentável do país, tema do próximo item deste estudo.

\section{CRITÉRIOS DE SUSTENTABILIDADE DO MDL}

Atualmente, os projetos de MDL submetidos à aprovação da AND brasileira devem apresentar uma descrição da contribuição da atividade de projeto para o desenvolvimento sustentável, de acordo com o Anexo III da Resolução no 1 de 11 de Setembro de 2003, em conformidade com o Artigo 12.2 do Protocolo de Quioto à Convenção-Quadro das Nações Unidas sobre Mudança do Clima (MCT, 2003).

Este item aborda, sucintamente, o processo que originou os critérios do Anexo III, considerando os principais estudos e documentos utilizados. Desta forma, foram analisados os seguintes documentos:

- $\quad$ Criteria and Indicators for Appraising Clean Development Mechanism (CDM) Projects (THORNE, S., LA ROVERE, E. L. 1999).

- $\quad$ Proposta revisada de critérios e indicadores de elegibilidade para avaliação de projetos candidatos ao Mecanismo de Desenvolvimento Limpo (NOVAES, E. S. LA RIVERE, E. L. et al, 2002).

- $\quad$ Resolução $\mathrm{n}^{\circ} 1$ de 11 de setembro de 2003 (MCT, 2003). 
O primeiro documento, i.e. Criteria and Indicators for Appraising CDM Projects, foi publicado ainda antes das regras do MDL consolidarem-se, em Marraquesh. Nele, são propostos critérios de elegibilidade e de avaliação de projetos de MDL, não apenas relacionados ao desenvolvimento sustentável (em seu sentido como hoje é abordado no Anexo III, mencionado na seqüência), mas também regras gerais relacionadas ao cerne do mecanismo.

Desta forma, os autores propõem critérios de elegibilidade de projetos contemplando questões como tecnologia apropriada, definição da linha de base e medidas de desenvolvimento sustentável. Algumas destas questões seriam, posteriormente (i.e. na COP realizada em Marraquesh), definidas como regras gerais para o mecanismo.

Os autores dividem os critérios de elegibilidade em critérios para:

- $\quad$ Seleção de projetos de MDL

-

- Participação de projeto de MDL

-

- Verificação de projeto de MDL

- $\quad$ Creditação de projeto de MDL

- Questões financeiras

Foram apresentados vinte e seis critérios para a elegibilidade dos projetos de MDL, citados a seguir, seguidos de um $\mathrm{S}$ para critérios que, de forma geral, foram incorporados e de um $\mathrm{N}$ para aqueles que não foram incorporados pelas regras gerais do MDL, conforme definidas em Marraquesh ou pela AND brasileira.

- Critério 1: Atividades do projeto relacionadas à energia que se qualificam ao MDL $(\mathrm{N})$

- $\quad$ Critério 2: Projetos de seqüestro que se qualificam ao MDL (N)

- Critério 3: Creditação retroativa $(\mathrm{N})$

- $\quad$ Critério 4: Benefícios reais e mensuráveis (S)

$\bullet$

- $\quad$ Critério 5: Integridade das emissões e da linha de base (S)

-

- Critério 6: Linhas de base "arrastadas" e incentivos perversos (S)

- Critério 7: Desenvolvimento Sustentável (S)

- Critério 8: MDL e políticas públicas nacionais (S)

- $\quad$ Critério 9: Limites de complementaridade (S)

$\bullet$

- Critério 10: 'Ar quente' (N)

$\bullet$

- $\quad$ Critério 11: Equiidade regional (N) 
- Critério 12 : Capacidade de participar no MDL (N)

- $\quad$ Critério 13: Participação voluntária (S)

- $\quad$ Critério 14: Participação local e nacional no MDL (N)

$\bullet$

- $\quad$ Critério 15: Aceitação do projeto MDL (N)

$\bullet$

- $\quad$ Critério 16: Soberania (S)

.

- Critério 17: Creditação aos projetos de MDL e seguro (S)

$\cdot$

- $\quad$ Critério 18: Fugas (S)

$\bullet$

- Critério 19: Auditoria de projetos de MDL (S)

$\bullet$

- Critério 20: Facilitação de projetos de MDL (N)

$\bullet$

- $\quad$ Critério 21: Relatórios de projeto de MDL (S)

$\bullet$

- $\quad$ Critério 22: Benefícios de redução de emissões (N)

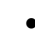

- $\quad$ Critério 23: Adicionalidade financeira (S)

.

- Critério 24: Adicionalidade de investimento (S)

$\bullet$

- $\quad$ Critério 25: Custos de transação e custos administrativos (N)

:

- $\quad$ Critério 26: Custo-eficácia (N)

Além dos 26 critérios de elegibilidade elencados acima, foram propostos critérios para monitorar os projetos após sua implementação. A proposta contemplou a atribuição de um valor, considerando o resultado obtido e o esperado, que variaria de $-100 \%$ a $+100 \%$ e dependeria de atribuições específicas a cada indicador. Os indicadores relacionam-se ao desenvolvimento sustentável, mais especificamente às questões de sustentabilidade ambiental, social, econômica e tecnológica.

Os oito indicadores sugeridos foram:

- Indicador 1 - Contribuição para a mitigação das Mudanças Climáticas Globais;

- $\quad$ Indicador 2 - Contribuição para a sustentabilidade ambiental local;

- $\quad$ Indicador 3 - Contribuição para a geração líquida de emprego;

- $\quad$ Indicador 4 - Contribuição para a sustentabilidade da balança de pagamentos;

- $\quad$ Indicador 5 - Contribuição para a sustentabilidade macroeconômica;

- $\quad$ Indicador 6 - Eficácia de Custo; 
- $\quad$ Indicador 7 - Contribuição para a auto-suficiência tecnológica;

- $\quad$ Indicador 8 - Contribuição para o uso sustentável dos recursos naturais (THORNE, S.; LA ROVERE, E.L., 1999)

A avaliação de projetos implementados, conforme sugerida, não foi efetivada oficialmente no Brasil. No entanto, alguns dos indicadores sugeridos foram incorporados, como veremos adiante, à fase de aprovação do projeto pela AND brasileira. Além destes, uma variação foi proposta, considerando a redução de emissões de cada projeto, de forma que se obteria o valor do benefício dos indicadores por emissão evitada, i.e., uma forma de medir o benefício específico por emissões. Para visualizar os resultados de uma avaliação considerando os indicadores propostos, se utilizaria uma figura de "floco de neve", conforme apresentado na Figura 1.

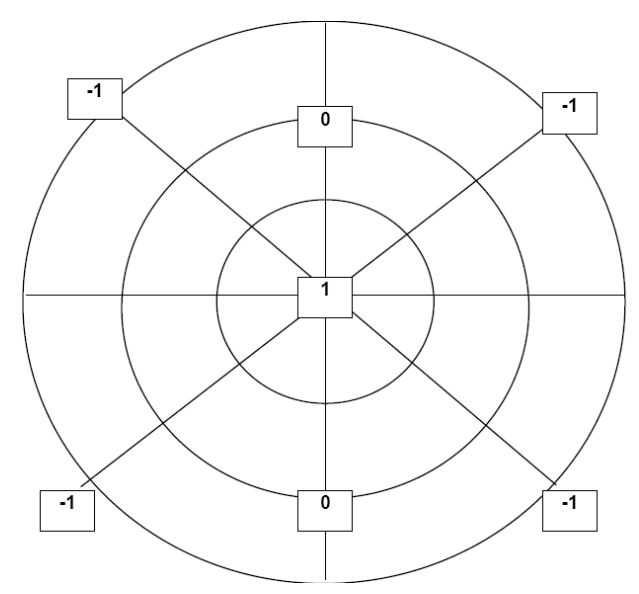

Figura 1: Representação dos resultados em "floco de neve" Fonte: THORNE, S.; LA ROVERE, E.L., 1999

Quanto maior o beneficio relacionado ao critério específico, mais próximo ao centro da circunferência será representado o impacto. Quanto pior o impacto, mas próximo à extremidade da circunferência ele será representado. No caso de impacto nulo, a representação é feita sobre o 0 (zero). Ressalta-se que o benefício é comparado àquilo que ocorreria na ausência do projeto, i.e., na linha de base, e que esta linha de base deve ser determinada de forma conservadora e dinâmica, considerando a melhor opção que o proponente do projeto teria caso não implementasse o projeto de MDL.

Em relação ao foco específico deste trabalho, i.e., impactos ambientais locais e regionais, o documento claramente sugere que os projetos de MDL envolvem outros impactos ambientais, positivos ou negativos, afetando o nível de desenvolvimento local, regional ou nacional, de forma que estes efeitos poderiam incluir:

- $\quad$ Emissão de outros poluentes atmosféricos (SOx, NOx, CO, HC, etc)

- $\quad$ Produção de resíduos sólidos

- Descarga de efluentes líquidos

- Uso de recursos naturais

$\cdot$

- $\quad$ Impactos sobre a biodiversidade (THORNE, S.; LA ROVERE, E.L., 1999) 
O segundo documento avaliado, i.e., Proposta revisada de critérios e indicadores de elegibilidade para avaliação de projetos candidatos ao MDL, foi desenvolvido por uma equipe da COPPE/UFRJ a pedido do Ministério de Meio Ambiente. O objetivo era estabelecer critérios de avaliação para projetos de redução de gases de efeito estufa (GEE), tendo como objetivos principais:

- Servir como proposta de discussão no âmbito da Comissão Interministerial de Mudança Global do Clima, tendo em vista que uma de suas competências é definir critérios de elegibilidade para projetos MDL adicionais àqueles formulados pelo Comitê Executivo Internacional. Esta definição deve adequar-se tanto à Convenção Quadro sobre Mudança do Clima como à política brasileira de desenvolvimento sustentável;

Apoiar o MMA na análise de projetos que contribuam para a redução da concentração de gases de efeito estufa na atmosfera (MMA, 2002).

Os critérios estabelecidos no documento basearam-se no estudo mencionado anteriormente (i.e. THORNE, S.; LA ROVERE, E.L., 1999) e foram também fruto de discussões realizadas durante um debate promovido pela CIMGC, em 2001.

A proposta original estabeleceu 4 critérios de elegibilidade de caráter eliminatório (que foram reduzidos para 2 na versão final), 8 indicadores de sustentabilidade e 3 indicadores de viabilidade operacional, ambos de caráter classificatório. Nota-se aqui que, em relação ao primeiro documento mencionado, houve uma redução considerável de critérios de elegibilidade. Um dos prováveis motivos encontra-se no fato de que, no momento em que foi estabelecido o documento do MMA, o encontro de Marraquesh já havia ocorrido e, consequentemente, regras gerais do MDL já haviam sido definidas. Desta forma, os critérios propostos em 2002 seriam adicionais àqueles estabelecidos para o MDL (que contemplaram alguns dos itens sugeridos em THORNE, S.; LA ROVERE, E.L., 1999), buscando orientar os critérios nacionais de avaliação de projetos MDL.

Dentro desta nova proposta, foram apresentados os seguintes critérios, obrigatórios, de elegibilidade (como acima, acompanhados de um S ou N, indicando sua adoção atual):

- $\quad$ Critério 1: Setores de atividade de projetos qualificáveis para o MDL (S)

$\bullet$

- Critério 2: Reduções de emissões reais e mensuráveis em relação ao cenário de referência $(S)$

Foram também propostos critérios para priorização de projetos, em função de suas características. Estes indicadores seriam classificatórios, e não eliminatórios como os anteriores. Sugeriu-se uma classificação por meio de pontos atribuídos aos projetos, variando de -3 a +3 . O extremo negativo denota um afastamento grande do atendimento ao indicador, zero (0) indica que não houve mudanças no cenário de projeto em relação ao cenário de referência e +3 demonstra o atendimento total ao indicador. $-2,+2,-1$ e +1 são valores intermediários (MMA, 2002). Os indicadores propostos foram os seguintes:

- Indicador 1: Contribuição para a mitigação das mudanças climáticas globais;

$\bullet$

- Indicador 2: Contribuição para a sustentabilidade ambiental local; 
- Indicador 3: Contribuição para a geração líquida de empregos;

- Indicador 4: Impactos na distribuição de renda;

$\bullet$

- $\quad$ Indicador 5: Contribuição para a sustentabilidade do balanço de pagamento;

$\bullet$

- Indicador 6: Contribuição para a sustentabilidade macroeconômica;

$\bullet$

- Indicador 7: Custo-efetividade;

$\bullet$

- $\quad$ Indicador 8: Contribuição para a auto-suficiência tecnológica

Um esquema de priorização de projetos nunca foi implementado no Brasil, de forma que os projetos são avaliados pela CIMGC, e tem sua recomendação (de aprovação ou não) emitida em função da ordem de apresentação à comissão, i.e., os projetos entregues antes serão avaliados antes. É interessante notar que parte destes critérios foi incorporada ao processo de aprovação da AND brasileira, não em sentido de priorização de projetos, mas como itens cuja demonstração é necessária para a obtenção da Carta de Aprovação, como será visto adiante.

Em 2003, a CIMGC publicou a primeira, de uma série (que até a conclusão deste trabalho, em Janeiro de 2011, soma nove) de resolução a respeito das regras nacionais do MDL. Estas resoluções, muitas vezes, apenas incorporam novas regras gerais do MDL, que são decididas nas reuniões do CE. A Resolução $n^{0} 1$ de 11 de setembro de 2003 indica que os proponentes do projeto de MDL deverão enviar à Secretaria Executiva da Comissão Interministerial de Mudança Global do Clima, dentre outros documentos:

1. O documento de concepção do projeto na forma determinada pelo Conselho Executivo do Mecanismo de Desenvolvimento Limpo, estabelecido no âmbito da ConvençãoQuadro das Nações Unidas sobre Mudança do Clima e, para fins de aprovação da atividade de projeto pela Comissão, na forma do Anexo II. Adicionalmente, como elemento informativo à Comissão Interministerial de Mudança Global do Clima, deve constar no documento de concepção do projeto uma descrição da contribuição da atividade de projeto para o desenvolvimento sustentável de acordo com o Anexo III a esta resolução e em conformidade com o Artigo 12.2 do Protocolo de Quioto à Convenção-Quadro das Nações Unidas sobre Mudança do Clima (MCT, 2009).

O Anexo III - Contribuição da Atividade de Projeto para o Desenvolvimento Sustentável indica que deverão ser descritas se, e como a atividade de projeto proposta contribuirá para o desenvolvimento sustentável, no que diz respeito a cinco aspectos:

a. Contribuição para a sustentabilidade ambiental local. Avalia a mitigação dos impactos ambientais locais (resíduos sólidos, efluentes líquidos, poluentes atmosféricos, dentre outros) propiciada pelo projeto em comparação com os impactos ambientais locais estimados para o cenário de referência.

b. Contribuição para o desenvolvimento das condições de trabalho e a geração líquida de empregos. Avalia o compromisso do projeto com responsabilidades sociais e trabalhistas, programas de saúde e educação e defesa dos direitos civis. Avalia, também, o incremento no nível qualitativo e quantitativo de empregos (diretos e indiretos) comparando-se o cenário do projeto com o cenário de referência. 
c. Contribuição para a distribuição de renda. Avalia os efeitos diretos e indiretos sobre a qualidade de vida das populações de baixa renda, observando os benefícios socioeconômicos propiciados pelo projeto em relação ao cenário de referência.

d. Contribuição para capacitação e desenvolvimento tecnológico. Avalia o grau de inovação tecnológica do projeto em relação ao cenário de referência e às tecnologias empregadas em atividades passíveis de comparação com as previstas no projeto. Avalia também a possibilidade de reprodução da tecnologia empregada, observando o seu efeito demonstrativo, avaliando, ainda, a origem dos equipamentos, a existência de royalties e de licenças tecnológicas e a necessidade de assistência técnica internacional.

e. Contribuição para a integração regional e a articulação com outros setores. A contribuição para o desenvolvimento regional pode ser medida a partir da integração do projeto com outras atividades socioeconômicas na região de sua implantação (MCT, 2003).

Como pode ser notado, os critérios consolidam um resumo da essência de critérios de indicadores anteriormente propostos em THORNE, S.; LA ROVERE, E.L. (1999) e NOVAES, E. S., LA ROVERE, E. L. et al (2002). Houve, de fato, um esvaziamento de parte das propostas originais, mas, por outro lado, a essência de boa parte delas pode ser notada nas regras hoje em vigor.

Uma breve menção ao mercado voluntário de carbono será feita na seqüência, buscando avaliar se este mercado, que segue paralelamente ao criado pelo Protocolo de Kyoto e pelo MDL, também se norteia, em parte, por princípios e critérios relacionados ao desenvolvimento sustentável local e regional.

\section{METODOLOGIA DE AVALIAÇÃO DE PROJETOS}

Considerando o conteúdo do Anexo III, como definido pela CIMGC, assim como a representação gráfica de "floco de neve" proposta em THORNE, S., LA ROVERE, E. L. (1999), além de alguns indicadores propostos no mesmo documento e em NOVAES, E. S., LA ROVERE, E. L. et al. (2002), serão avaliados os Anexos III de projetos de energia renovável que tiveram emitida a carta de aprovação pela AND brasileira.

Para estes projetos, serão atribuídos + (quando o impacto for positivo), - (quando o impacto for negativo) ou 0 no caso de impacto nulo, para oito critérios específicos, descritos a seguir. Os oito indicadores são relacionados ao controle da poluição local e regional e consideram os impactos secundários dos projetos de MDL avaliados.

- $\quad$ Impacto à emissão de $\mathrm{CO}$ (representado por $\mathrm{CO})$;

- $\quad$ Impacto à emissão de NOx (representado por NOx);

$\bullet$

- $\quad$ Impacto à emissão de $\mathrm{SOx}$ (representado por SOx);

$\bullet$

- $\quad$ Impacto à emissão de MP (representado por MP),

$\bullet$

- $\quad$ Impacto à emissão de Hidrocarbonetos (representado por HC); 
- Impacto sobe recursos hídricos (representado por RH);

- Impacto sobe a fauna (representado por Fn);

- Impacto sobe a flora (representado por $\mathrm{Fl})$.

De forma semelhante à sugerida em THORNE, S., LA ROVERE, E. L. (1999), quanto maior o beneficio relacionado ao critério específico, mais próximo ao centro da circunferência será representado o impacto (neste caso, será atribuído o + , que se localizará no centro da circunferência). Quanto pior o impacto, mas próximo à extremidade da circunferência será representado o impacto (neste caso, será atribuído o -, que se localizará na extremidade da circunferência). No caso de impacto nulo, a representação é feita sobre o 0 (zero).

Os projetos avaliados, como mencionado acima, foram aprovados pela AND. Os seguintes projetos foram considerados:

1. Projeto de Energia Eólica Rosa dos Ventos

2. Projeto GEEA de Central Elétrica de Biomassa de 5MW

3. Projeto "Santa Cruz S/A - Açúcar e Álcool - Projeto de Cogeração"

4. PCH Santa Edwiges III

5. Projeto de Repotenciação Energética da UHE Mascarenhas

Estes projetos, que são relacionados à geração de energia com o uso de bagaço, eólica, outras biomassas, Pequenas Centrais Hidroelétricas, Usina Hidroelétrica, não serão apresentados em detalhes, de forma que apenas o primeiro item de seus Anexos III, i.e., contribuição para a sustentabilidade ambiental local e regional, foi avaliado. No entanto, é interessante notar que a lógica dos projetos de MDL relacionados à geração de energia com fontes renováveis está diretamente ligada à menor necessidade de geração por meio das fontes tradicionais. Em outras palavras, à medida que mais energia (em MWh) é disponibilizada ao sistema interligado nacional (SIN), por meio de fontes renováveis com baixa emissão de CO2equivalente por MWh gerado, diminui a necessidade de geração de eletricidade por meio das usinas já ligadas ao sistema, ou das que seriam construídas num futuro próximo, principalmente as usinas termoelétricas à carvão ou gás natural (que são as mais fáceis de serem "ligadas", "desligadas", construídas em menor tempo e são acionadas quando há uma maior demanda de energia, servindo, principalmente, de apoio às hidroelétricas). Desta forma, quando falamos em adicionar energia renovável ao SIN, devemos pensar que esta energia ocupa o lugar de uma energia que é então evitada, i.e., àquela gerada por fontes mais emissoras de GEE.

\section{RESULTADOS E DISCUSSÃO}

Considerando o Anexo III de cada projeto selecionado, os critérios estabelecidos para a avaliação e a representação gráfica por meio da figura de "floco de neve", foram obtidos os seguintes resultados: 


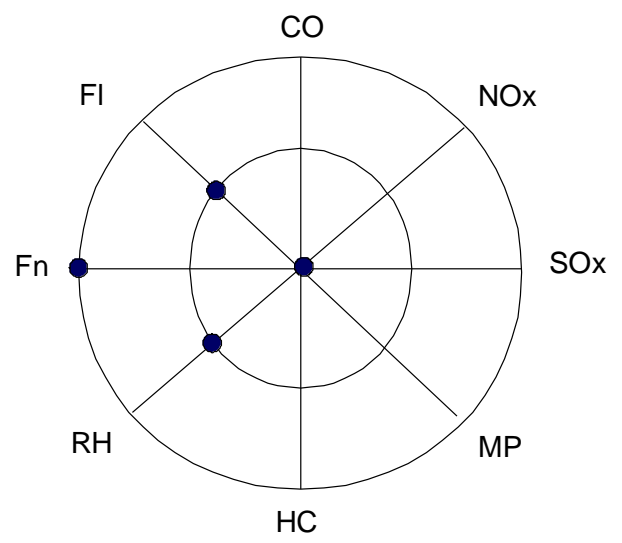

Figura 2: Projeto de Energia Eólica Rosa dos Ventos

Fonte: Elaboração própria

O projeto 1 resulta em benefícios regionais em diversos dos critérios avaliados, principalmente pelo fato de evitar a combustão de combustíveis fósseis, que trariam à atmosfera um aumento de CO, NOx, SOx, MP e HC (além dos GEE). Impacto negativo é notado sobre a fauna, principalmente sobre aves na região.

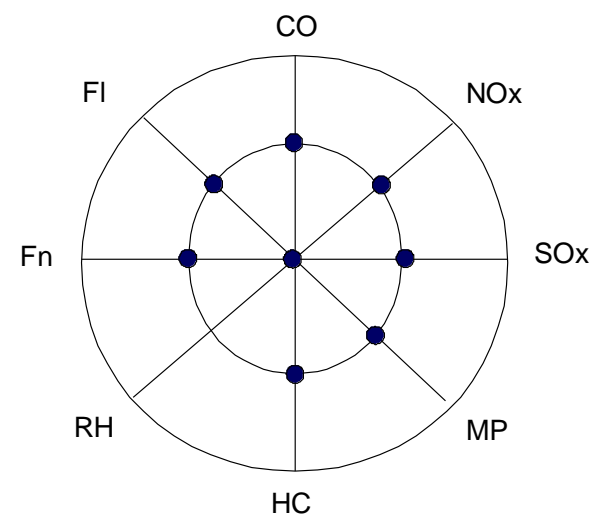

Figura 3: Projeto GEE de Central Elétrica de Biomassa de 5MW

Fonte: Elaboração própria

O projeto 2 resulta em benefícios regionais, principalmente no que concerne aos impactos sobre recursos hídricos, já que dará uma destinação diferente a um resíduo que impactava os recursos da região. Impactos relacionados aos critérios $\mathrm{CO}, \mathrm{NOx}, \mathrm{SOx}, \mathrm{MP}$ e HC foram considerados nulos pelo fato de que, apesar de o projeto evitar a combustão de combustíveis fósseis, trariam à atmosfera um aumento destes poluentes, a emissão dos mesmos poluentes aumentará na região em função da queima do resíduo (algo que não ocorreria na linha de base). Desta forma, com base em uma simplificação da análise, considerou-se que um impacto anulará o outro (novamente, desconsiderando o impacto positivo sobre as emissões de GEE - positivo por emitir $\mathrm{CO}_{2}$ de origem biogênica e não fóssil). É interessante mencionar que, adicionalmente ao desenvolvimento do projeto MDL, a usina Santa Cruz aderiu a um Protocolo Agroambiental, formalizado junto a Secretaria do Meio Ambiente o Estado de São Paulo, o que implica na elaboração e execução de um plano de ação que considera aspectos ambientais locais. 


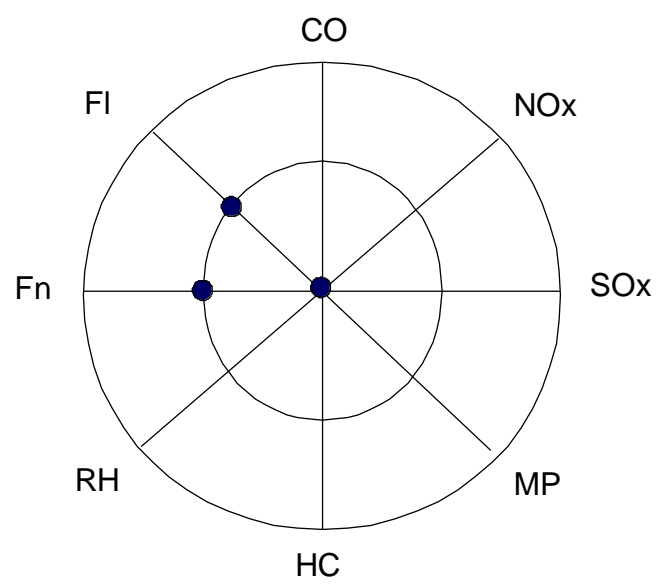

Figura 4: Projeto "Santa Cruz S/A - Açúcar e Álcool - Projeto de Cogeração"

Fonte: Elaboração própria

$\mathrm{O}$ projeto 3 resulta em benefícios regionais, principalmente no que concerne aos impactos sobre recursos hídricos e emissão de MP, já que, como conseqüência do projeto, haverá menor demanda de água no sistema e será instalado um filtro com maior capacidade de retenção de MP. Haverá uma melhora em relação, também, aos impactos relacionados aos critérios $\mathrm{CO}$, NOx, SOx, e HC, tendo em vista que a mesma emissão que ocorrerá no projeto, ocorreria na linha de base mas, adicionalmente, a emissão destes poluentes pela queima de combustíveis fósseis para a geração de energia, que seria gerada na ausência do projeto, será evitada.

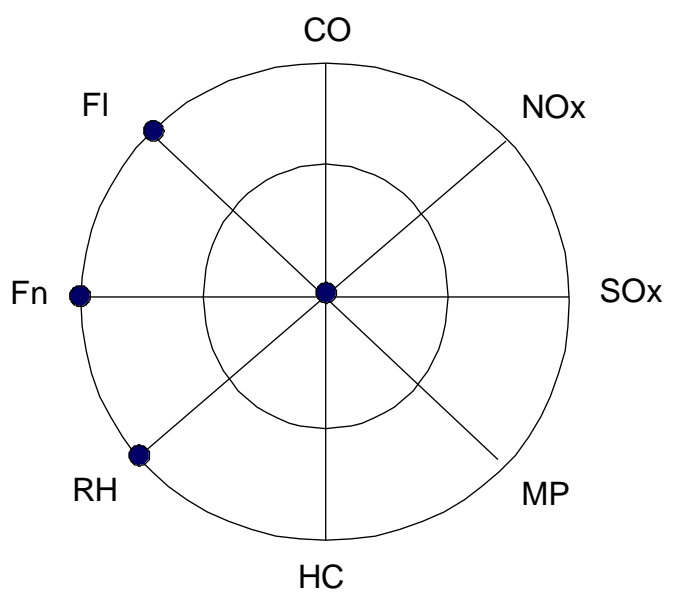

\section{Figura 5: Pequena Central Hidrelétrica Santa Edwiges III}

Fonte: Elaboração própria

$\mathrm{O}$ projeto 4 resulta em benefícios regionais, principalmente no que concerne aos impactos advindos da emissão de CO, NOx, SOx, MP e HC, tendo em vista que evitará a queima de combustíveis fósseis para a geração de energia. Causa impactos, no entanto, à flora, fauna e aos recursos hídricos, principalmente pela necessidade de represar um rio, e impactos associados à construção. 


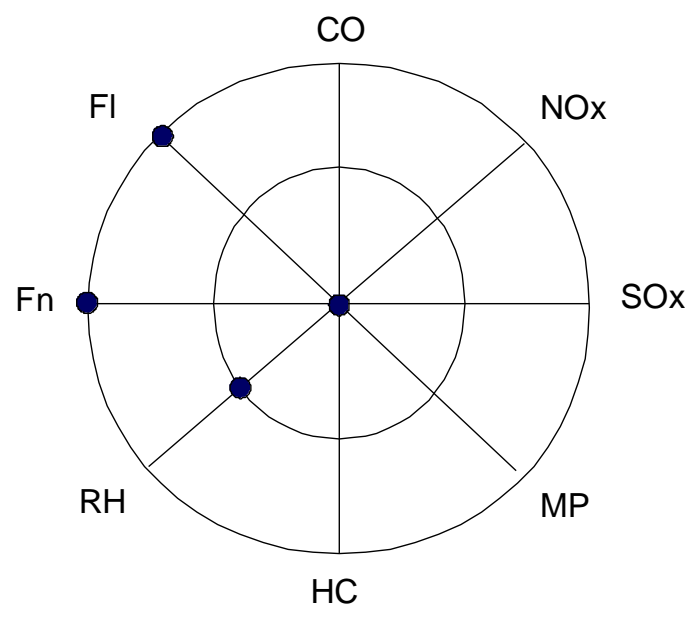

\section{Figura 6: Projeto de Repotenciação Energética da UHE Mascarenhas}

Fonte: Elaboração própria

O projeto 5 resulta em benefícios regionais, principalmente no que concerne aos impactos advindos da emissão de CO, NOx, SOx, MP e HC, tendo em vista que evitará a queima de combustíveis fósseis para a geração de energia, da mesma forma como no projeto mencionado anteriormente. Causa impactos, no entanto, à flora e à fauna devido aos impactos associados à construção. Este projeto não afetará os recursos hídricos, pois a área alagada não será ampliada.

Pelo exposto acima, notam-se importantes benefícios secundários de projetos relacionados à geração de energia com fontes renováveis, principalmente àqueles associados às emissões de poluentes locais e regionais. A quantidade líquida de emissões dos poluentes avaliados será reduzida, regionalmente, com a implementação dos projetos. Nota-se que alguns tipos de geração elétrica por fonte renovável apresentam menos impactos do que outros, nos critérios avaliados, notadamente os relacionados à energia eólica e à queima de bagaço.

\section{CONCLUSÕES}

A avaliação de critérios relacionados à poluição ambiental local e regional é uma ferramenta de gestão ambiental importante para que se identifiquem as melhores alternativas de projetos de redução de emissões, no que concernem os impactos secundários. Tendo em vista que o objetivo principal dos mecanismos de geração de créditos de carbono é reduzir a emissão de GEE, é notável o esforço para atribuir benefícios locais e regionais ao MDL.

Os critérios estabelecidos para o Anexo III contemplam, em essência, os critérios sugeridos nos trabalhos que antecederam sua definição. Por outro lado, é notável a diminuição do peso de benefícios secundários no mecanismo, como critérios obrigatórios ou classificatórios, quando se comparam as idéias originais àquelas que de fato foram implementadas.

Ao mesmo tempo, devem ser valorizados os impactos secundários positivos advindos dos projetos de MDL, notados àqueles apresentados neste trabalho. Ressalta-se que os impactos ambientais positivos são extremamente relacionados ao menor consumo de combustíveis fósseis (não desconsiderando também a menor necessidade de produção dos mesmos) e aos impactos associados.

Desta forma, os benefícios da geração de energia pelas fontes renováveis avaliadas irão gerar, principalmente, um impacto ambiental positivo nas regiões do país onde mais se produz eletricidade por meio de usinas termoelétricas a carvão, i.e., no sul do país, ou em lugares onde se 
planeja construir novas termoelétricas utilizando este combustível (e.g. na costa do país, tendo em vista a possibilidade de importação de carvão).

Não deve ser desprezado também o benefício sobre a menor necessidade de geração utilizando outros combustíveis fósseis (e.g. diesel ou óleo combustível), mas estes são, de forma geral, mais empregados em sistemas elétricos isolados, i.e., não ligados ao SIN.

Considerando que o MDL ainda é o mecanismo de maior impacto no mercado de carbono, e que preconiza ações relacionadas ao desenvolvimento sustentável local e regional, seria interessante avaliar, no Brasil, in loco, se os projetos implementados de fato estão contribuindo para a sustentabilidade local e regional, como deveriam. Ao mesmo tempo, seria interessante avaliar se outros países exigem benefícios específicos atrelados à emissão da Carta de Aprovação do país e, caso sim, quais as principais semelhanças e diferenças em relação ao sistema brasileiro.

\section{REFERÊNCIAS}

1. AMARAL, P. C. Créditos de carbono e suinocultura brasileira: situação atual e possibilidades advindas do mecanismo de desenvolvimento limpo. Trabalho apresentado à Faculdade de Ciências Agrárias Veterinárias - UNESP, Campus de Jaboticabal, para graduação em Agronomia. 2007. Disponível em <www.pluridoc.com>. Acesso em: 05/08/2009.

2. BRAGA, B. et al. Introdução à Engenharia Ambiental. Editora: PRENTICE-HALL. 2005.

3. HAMILTON, K., SJARDIN, M, SHAPIRO, A., MARCELLO, T. Fortifying the Foundation: State of the Voluntary Carbon Markets 2009. A Report by Ecosystem Marketplace \& New Carbon Finance. 20 May 2009.

4. LA ROVERE, E. L. 2009. Material da disciplina Poluição Ambiental, oferecida aos alunos de mestrado e doutorado do Programa de Planejamento Energético da COPPE/ Universidade Federal do Rio de Janeiro.

5. IPCC, 2007: Summary for Policymakers. In: Climate Change 2007: The Physical Science Basis. Contribution of Working Group I to the Fourth Assessment Report of the Intergovernmental Panel on Climate Change [Solomon, S., D. Qin, M. Manning, Z. Chen, M. Marquis, K.B. Averyt, M.Tignor and H.L. Miller (eds.)]. Cambridge University Press, Cambridge, United Kingdom and New York, NY, USA.

6. IPCC, 2007: Summary for Policymakers. In: Climate Change 2007: Impacts, Adaptation and Vulnerability. Contribution of Working Group II to the Fourth Assessment Report of the Intergovernmental Panel on Climate Change, M.L. Parry, O.F. Canziani, J.P. Palutikof, P.J. van der Linden and C.E. Hanson, Eds., Cambridge University Press, Cambridge, UK, 7-22.

7. IPCC, 2007: Summary for Policymakers. In: Climate Change 2007: Mitigation. Contribution of Working Group III to the Fourth Assessment Report of the Intergovernmental Panel on Climate Change [B. Metz, O.R. Davidson, P.R. Bosch, R. Dave, L.A. Meyer (eds)], Cambridge University Press, Cambridge, United Kingdom and New York, NY, USA.

8. MCT. Comissão Interministerial de Mudança Global do Clima. Disponível em <http://www.mct.gov.br/clima/ingles/comunic/cimgc.htm>. Acesso em 07/08/2009. 
9. MCT. Resolução $\mathrm{n}^{\circ} 1$ de 11 de setembro de 2003. 2003. Disponível em <http://www.mct.gov.br/clima>. Acesso em 20/08/2009.

10. MOREIRA, H. M., GIOMETTI, A. B. R. 2008. O Protocolo de Kyoto e as possibilidades de inserção do Brasil no mecanismo de desenvolvimento limpo através de projetos em energia limpa. Contexto internacional. Rio de Janeiro, vol. 30, no 1, janeiro/abril 2008, p. 9-47. Disponível em <http://www.scielo.br/pdf/cint/v30n1/01.pdf>. Acesso em 02/08/2009.

11. NOVAES, E. S., LA ROVERE, E. L. et al. Proposta revisada de critérios e indicadores de elegibilidade para avaliação de projetos candidatos ao mecanismo de desenvolvimento limpo (MDL). Ministério do Meio Ambiente. Abril de 2002. Disponível em <http://www.centroclima.org.br/new2/ccpdf/criterio.pdf>. Acesso em: 03/08/2009.

12. The World Bank. 2009. STATE AND TRENDS OF THE CARBON MARKET 2009. Washington, D.C. May 2009. Disponível em: $<$ http://wbcarbonfinance.org/docs/State__Trends_of_the_Carbon_Market_2009FINAL_26_May09.pdf>. Acesso em: 21/08/09.

13. THORNE, S.; LA ROVERE, E.L., Criteria and Indicators for Appraising Clean Development Mechanism (CDM) Projects. HELIO INTERNATIONAL. 1999. Disponível em: <http://www.centroclima.org.br/new2/ccpdf/CDM_Appraisal.PDF>. Acesso em 03/08/2009.

14. UNFCCC, 2009. About CDM. 2009. Disponível em <http://cdm.unfccc.int/about/index.html> Acesso em 06/08/2009.

15. UNFCCC. Designated National Authorities. 2009. Disponível em <http://cdm.unfccc.int/DNA/index.html>. Acesso em 06/08/2009.

16. SANTOS, M. A. 2009. Material da disciplina Poluição Ambiental, oferecida aos alunos de mestrado e doutorado do Programa de Planejamento Energético da COPPE/ Universidade Federal do Rio de Janeiro. 